\title{
Surgical Technique and Clinical Analysis of Twelve Cases of Isolated Laparoscopic Resection of the Hepatic Caudate Lobe
}

\author{
Bin Jin (1D), Zhengchen Jiang, Sanyuan Hu (D), Gang Du, Binyao Shi, \\ Du Kong, and Jinhuan Yang
}

Qilu Hospital of Shandong University, Jinan, Shandong 250012, China

Correspondence should be addressed to Bin Jin; jinbin9494@126.com and Sanyuan Hu; husanyuan1962@hotmail.com

Received 1 September 2017; Accepted 5 December 2017; Published 16 January 2018

Academic Editor: Joseph F. Buell

Copyright (c) 2018 Bin Jin et al. This is an open access article distributed under the Creative Commons Attribution License, which permits unrestricted use, distribution, and reproduction in any medium, provided the original work is properly cited.

\begin{abstract}
Objective. To describe the surgical procedures of laparoscopic caudate lobectomy and analyze its clinical efficiency for treating cancer. Methods. Twelve consecutive patients of hepatocellular carcinoma, hepatic hemangioma, and focal nodular hyperplasia who received laparoscopic caudate lobectomy in Qilu Hospital of Shandong University from January 2013 to January 2017 were included in this study. The clinical data, intraoperative parameters, and postoperative outcomes were assessed. Results. All 12 patients received totally laparoscopic technique. The operative time was $140.8 \pm 95.34$ minutes. The average estimated blood loss was $97.92 \pm 90.54 \mathrm{ml}$, and no blood transfusions were required. The mean duration of hospital stay was $9.17 \pm 2.88$ days. There was no perioperative complication or patient mortality in this series. Conclusions. Laparoscopic caudate lobectomy is safe and feasible in the selected patients.
\end{abstract}

\section{Introduction}

Laparoscopic surgery, as an important part for the minimally invasive surgery, has been extensively used in clinical practices nowadays. In 1991, Reich et al. initially describes their technique on laparoscopic hepatectomy in three women [1]. Two years later, Wayand and Woisetschiager reported their experiences on removal of a solitary liver metastasis by laparoscopic technique in a 63-year old patient [2]. In China mainland, laparoscopic hepatectomy was firstly performed in 1994 [3]. Afterwards, such technique has been commonly used in our country.

The scope of liver resection ranged from benign lesions to hemihepatectomy, difficult segmental resection, and even hepatectomy for liver transplantation. In the past decades, caudate lobectomy was considered as a challenge as the caudate lobe of liver was deep in site and was adjacent to the inferior vena cava (IVC), portal vein, and hepatic veins $[4,5]$. Nowadays, laparoscopic caudate lobectomy is no longer a restricted zone with the advances of the medical technique [6, 7]. However, there are still some difficulties in the procedures especially the hemorrhage. In this study, we reported our experiences on 12 cases who underwent laparoscopic caudate lobectomy.

\section{Materials and Methods}

2.1. Patients. Twelve patients admitted to our department from January 2013 to January 2017 were included in this study. Among the 12 cases, 4 (33.33\%) were diagnosed with cavernous hemangioma, 7 (58.33\%) with primary liver cancer, and $1(8.33 \%)$ with focal nodular hyperplasia in liver. All cases showed no ascites. The liver function was classified as ChildPugh A class. Each patient signed the informed consent. The study protocols were approved by the Ethics Committee of Qilu Hospital of Shandong University.

2.2. Surgical Procedures. The patients were placed in a supine position (30 degrees anti-Trendelenburg). Pneumoperitoneum was established through a subumbilical port with a pressure of $12 \mathrm{mmHg}$. Then six-port technique was used (Figure 1, T1-T6). The Trocar and laparoscope were inserted. 


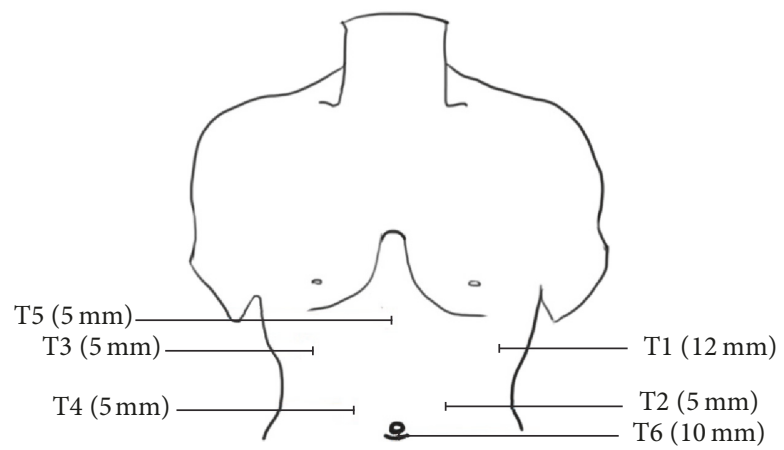

FIgURE 1: Port position for laparoscopic isolated caudate lobectomy.

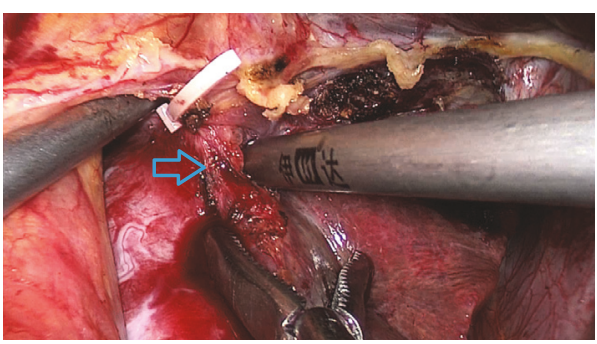

(a)

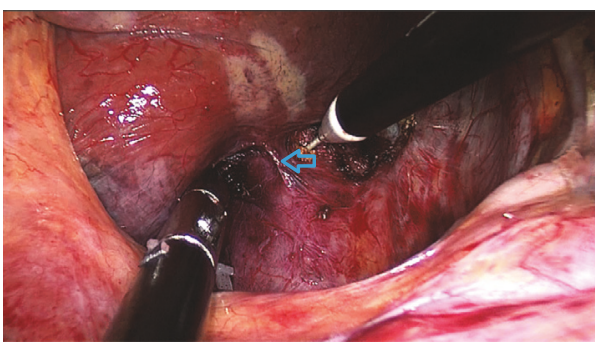

(c)

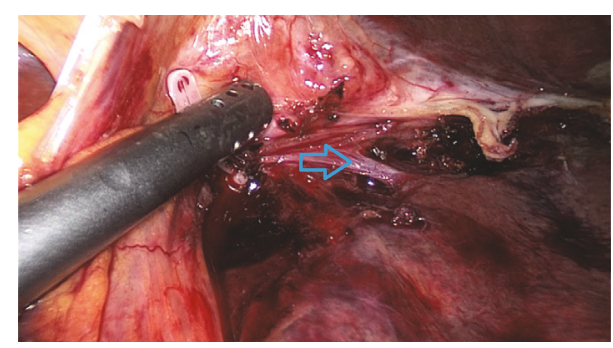

(b)

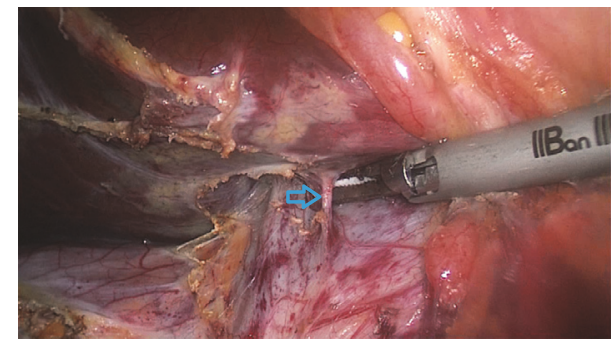

(d)

FIGURE 2: Transection of the CL branches from the IVC or porta hepatis. (a),(b) Dissection of SHV. (c), (d) Dissection of Glissonian branches of the CL.

For the short hepatic vein, we firstly open the lesser omentum to expose the tumor in the caudate lobe. Then the third porta of liver was dissected, and then the short hepatic veins in conjunction with the caudate lobe were dissected. Subsequently, the short hepatic veins were clamped using a Hem-o-lok (Figures 2(c) and 2(d)). For the management of the first and second porta hepatis, the vessels in conjunction with the caudate lobe including hepatic artery and portal vein were dissected and then clamped using the Hem-o-lok clamp and the absorbable clamp (Figures 2(a) and 2(b)). When separating the hepatic pedicle, the assistant can pull caudate lobe downwards to expose the Glissonian branches. The chief surgeon can ligate the branches one by one. This method reduced the risk of vascular injury and avoided the incidences of postoperative complications. Subsequently, an S-shaped retractor was used to pull the first porta hepatis to the right side (Figure 3(d)). Then the caudate lobe was transected using a combination of ultrasonic dissection from the left side. The large vessels and bile duct were clamped using a Hem-o-lok, absorbable clamp, and titanium clamp. The first porta hepatis was pulled to the left side. Liver tissues at the right side of the tumor in the caudate lobe were treated using a similar method (Figures 3(a)-3(c)). During the operation, special cares were taken to protect the IVC, the portal vein, and the bile duct. Then an intraperitoneal drainage tube was inserted. Finally, the specimen was placed in an endocatch bag and extracted through the subumbilical port.

\section{Results}

3.1. Patient Characteristics. Among the 12 cases, 7 (58.3\%) showed hepatic cirrhosis and 7 (58.3\%) showed chronic hepatitis B (Table 1). The surgery duration was $140.8 \pm$ $95.34 \mathrm{~min}$. The intraoperative blood loss was $97.92 \pm 90.54 \mathrm{ml}$. The mean hospitalization duration was $9.17 \pm 2.88$ days. No postoperative hemorrhage, liver failure, infection, or mortality was noticed. All the patients were followed up for a 


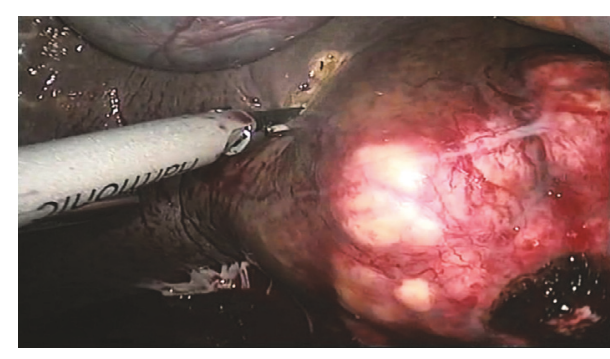

(a)

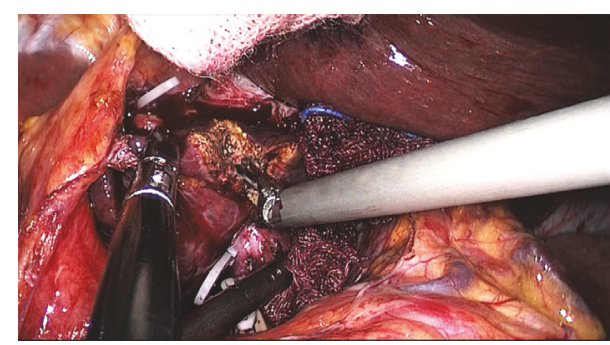

(c)

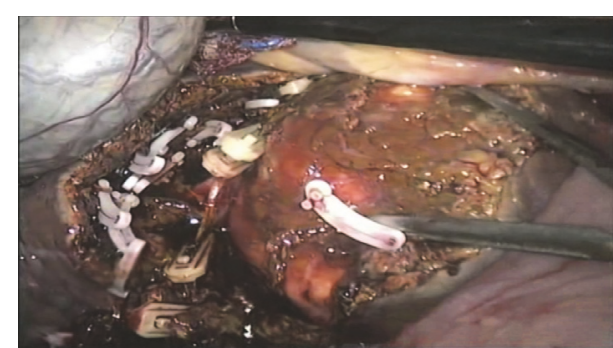

(b)

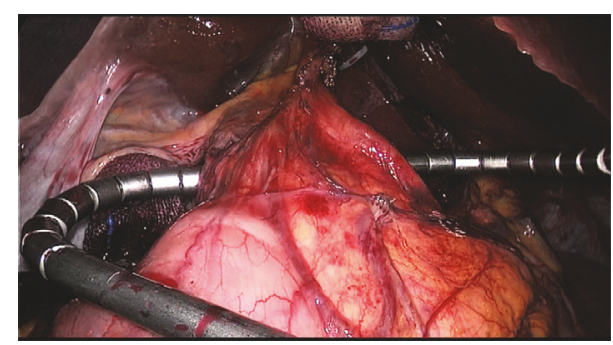

(d)

Figure 3: Transection of the CL parenchyma and technique of exposure to surgical vision. (a)-(c) Dissection of left or right of caudate lobe. (d) Place the S-shaped retractor to pull the hepatoduodenal ligament.

duration of 12-15 months. No recurrence was noticed in these patients.

Postoperative recovery of liver function showed that alanine aminotransferase (ALT) and aspartate aminotransferase (AST) were higher in all patients compared with the baseline levels. Despite ALT and AST showed decrease on postoperative days 3 and 5, the levels were still higher than the baseline levels. This may be related to the injury of the adjacent liver tissues in the process of operation or ischemiareperfusion injury caused by blocking the porta hepatis (Table 2).

\section{Discussion}

There are still some disputes about the scope for the caudate lobe. In 1955, Couinaud divided the liver into eight segments (S1-S8) according to the distribution pattern of the intrahepatic vessels, among which caudate lobe was defined as S1. In 1985, Kumon divided the caudate lobe into three sections, including the Spiegel lobe, the paracaval portion, and the caudate process [27]. The Spiegel lobe was located in a position behind the lesser omentum, to the left of the Arantius ligament. In addition, the paracaval portion that was attached to the anterior IVC surface through retrohepatic ligament and short hepatic veins was localized at the right side of the Spiegel lobe. As the smallest of the three sections, caudate process is a thin tongue-like projection that was localized between the IVC and the portal vein to the right of the paracaval section. The upper border of the caudate lobe extended to a position that was behind the major hepatic veins. To the best of our knowledge, it is still a challenge for the exposure of caudate lobe as it was adjacent to IVC, portal vein, and hepatic vein, which induces much blood loss or complications and high mortality rate after open surgery.
In 1987, Philipmonet et al. firstly performed laparoscopic cholecystectomy. Later, the technique is extensively used in clinical practice as it shows exciting characteristics such as minimally invasive, less blood loss, and slight injury. As the largest substantial organ in human body, liver has abundant blood supply such as proper hepatic artery and portal vein. Besides, its anatomical structure was rather complex and the hemostasis was difficult in clinical practice, which hampered the application of laparoscopic technique. In recent years, with the development of microsurgery, laparoscopic hepatectomy has been widely used in clinics [28-31]; however, laparoscopic caudate lobectomy is still involving harsh technical demanding. In the past decades, due to technical limitations, the majority of laparoscopic caudate lobectomy is mainly restricted to the anterior hepatic segment (S2-S6). In 2006, Dulucq et al. reported their experiences on laparoscopic approach for caudate lobectomy in 2 cases [32]. After a literature review until July 2017, we have only found 67 cases who underwent laparoscopic caudate lobectomy, and most of the studies are presented as case reports (Tables 3 and 4 ) $[8-23,25,26,32]$. In this study, we reported our experience on laparoscopic hepatic caudate lobectomy. The surgery was all successfully performed, with no cases transferred to the laparotomy. The surgical duration was $140.8 \pm 95.34 \mathrm{~min}$, and the intraoperative blood loss was $97.92 \pm 90.54 \mathrm{ml}$. The total hospitalization duration was $9.17 \pm 2.88$ days. After the surgery, no hemorrhage, liver failure, infection, or death was noticed. Based on our experiences, we suggested that surgeons should pay attention to the following aspects in clinical practice.

For the selection of laparoscopic approach, it should be based on the lesion site, size, and the liver function of the patients. In general, the left-sided laparoscopic approach is suitable for the Spiegel lobe and the patients with a tumor 


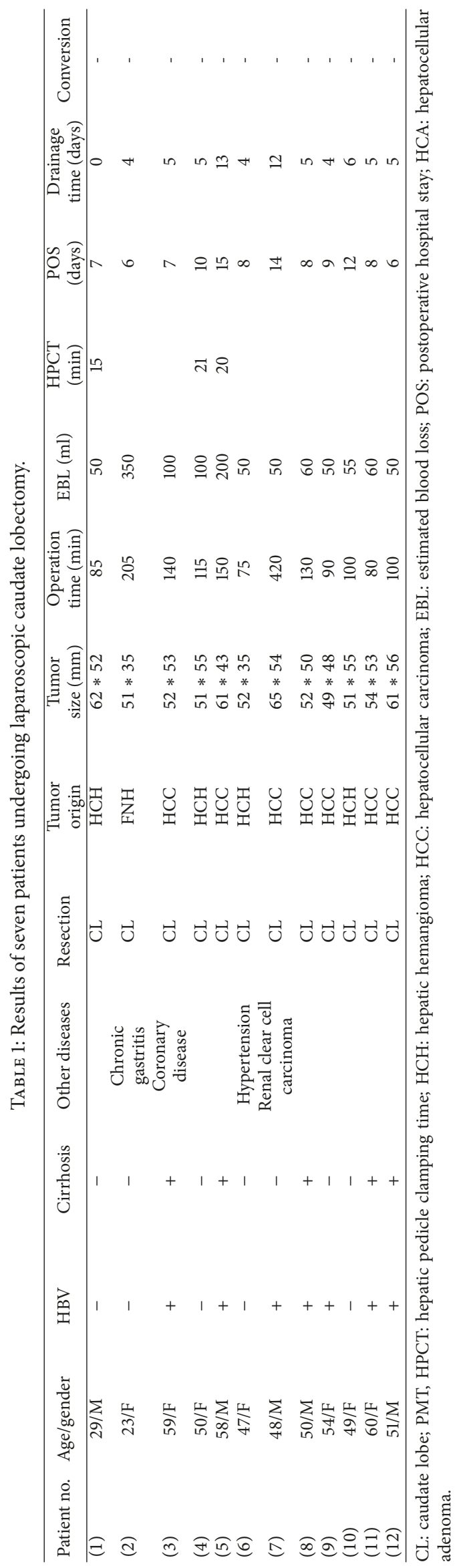




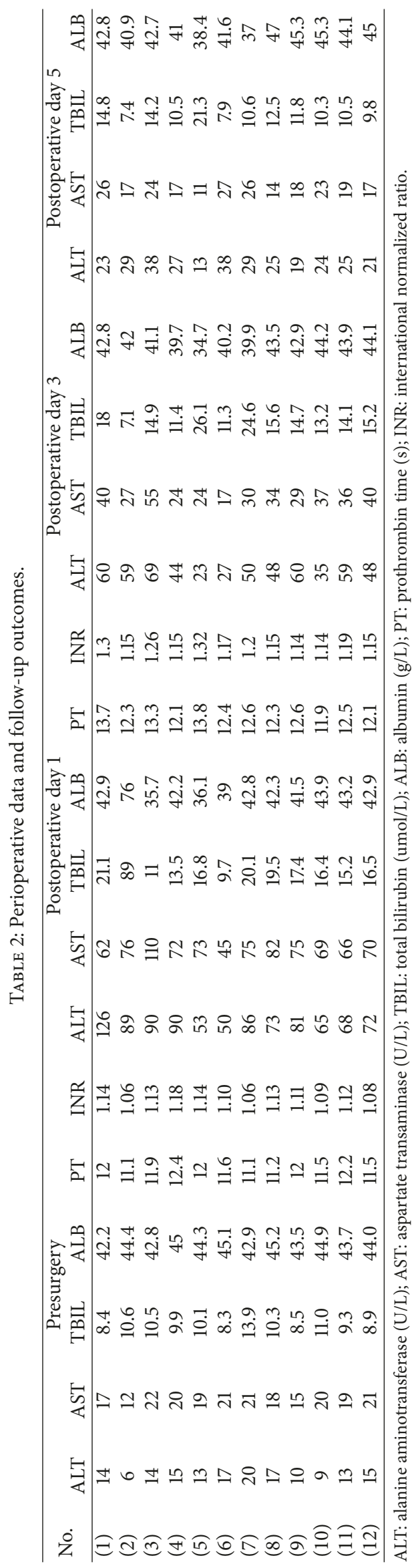




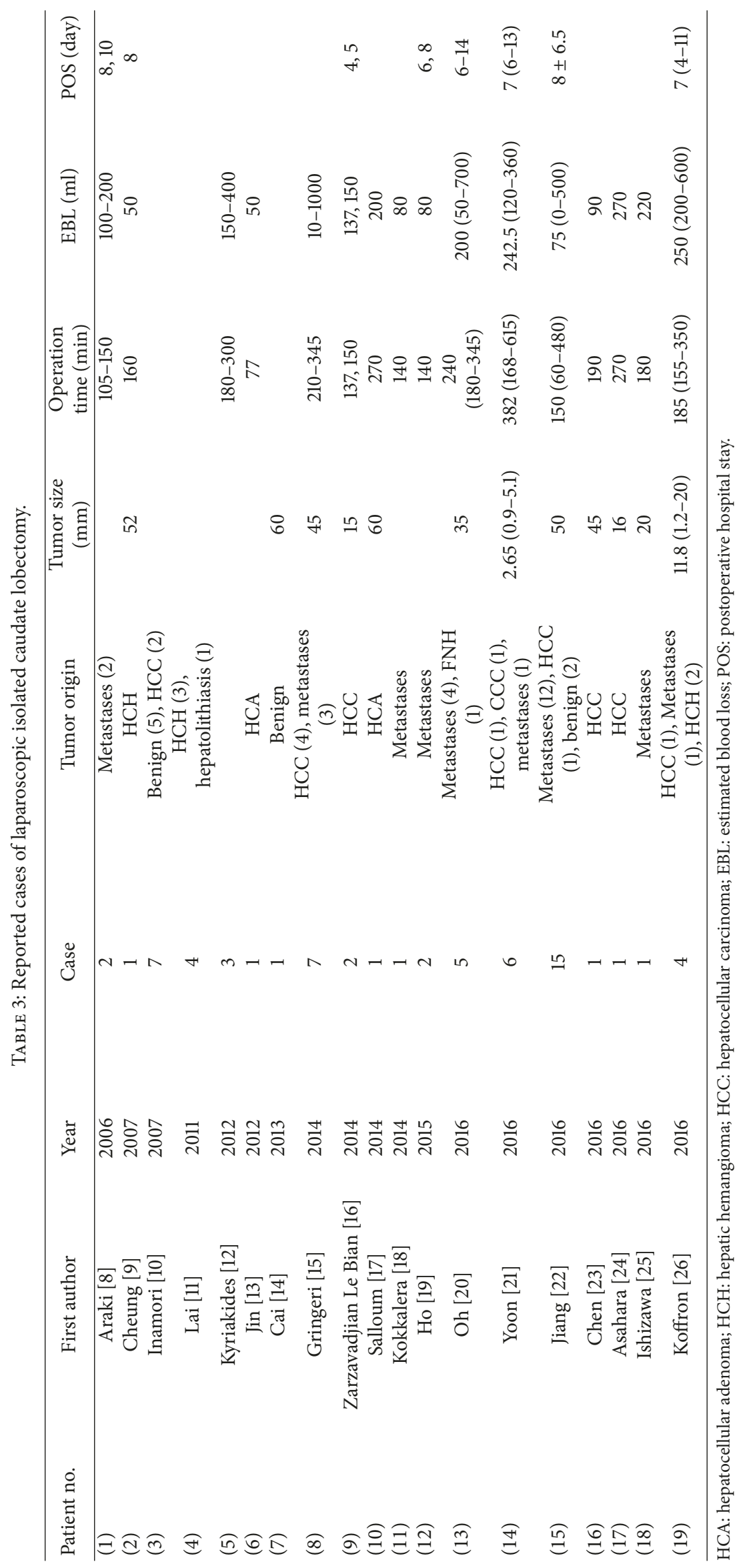


TABLE 4: Reported cases of laparoscopic isolated caudate lobectomy.

\begin{tabular}{lccc}
\hline No & First author & Mean op time (min) & Mean EBL (ml) \\
\hline 1 & Araki [8] & 127.5 & 150 \\
2 & Cheung [9] & 160 & 50 \\
6 & Jin [13] & 77 & 50 \\
9 & Zarzavadjian Le Bian [16] & 143.5 & 143.5 \\
10 & Gringeri [15] & 270 & 200 \\
11 & Kokkalera [18] & 140 & 80 \\
12 & Ho [19] & 140 & 80 \\
13 & Oh [20] & 240 & 200 \\
14 & Yoon [21] & 382 & 242.5 \\
15 & Jiang [22] & 150 & 75 \\
16 & Chen [23] & 190 & 90 \\
17 & Asahara [24] & 270 & 270 \\
18 & Ishizawa [25] & 180 & 220 \\
19 & Koffron [26] & 185 & 250 \\
\hline \multicolumn{1}{l}{} & Other reports $(n=14)$ & $189.64 \pm 77.77$ & $97.92 \pm 90.54$ \\
& This study $(n=10)$ & $140.8 \pm 95.34$ & $P=0.131$ \\
\hline
\end{tabular}

HCA: hepatocellular adenoma; CCC: cholangiocarcinoma; HCH: hepatic hemangioma; HCC: hepatocellular carcinoma; EBL: estimated blood loss.

diameter of $<3 \mathrm{~cm}$. The right-sided laparoscopic approach is mainly suitable for the paracaval lesions and the caudate process. The anterior approach and the combination between the left- and right-sided laparoscopic approaches are suggested for the cases with the whole caudate lobe involvement. Compared with the combination between the left- and right-sided laparoscopic approaches, the anterior approach is more suitable for the patients with large size lesions. Asahara et al. [24] proposed that patients with a lesion diameter of $>4 \mathrm{~cm}$ could receive anterior approach. Peng et al. [33] suggested anterior approach for the cases with massive lesions or involvement of inferior vena cava and short hepatic vines, as it could prevent the hepatic rotation and hepatic venous rupture. Thus, it is the best choice for the caudate lobectomy. On this basis, the combination of the left- and right-sided laparoscopic approaches is more suitable after taking the limitation of the telescope devices as it could help to free the caudate lobe in the tumor site, which prevents the vascular injuries.

Hemostasis and exposure of surgical field are crucial for those received caudate lobectomy. Vascular inflow to CL is derived from primary Glissonian branches originating from the right and left portal veins. Meanwhile, the hilar bifurcation branch mainly contributes to the supply of the paracaval portion and Spiegel lobe to the left portal veins and the caudate process on the right, which is convenient for blocking vessels. Studies have shown that the Glissonian branches of the $\mathrm{CL}$ are short and unfocused, forming a pedicle form when entering the CL. Therefore, when dealing with it, it should be close to the CL [12]. CL commonly has two arteries with one contributing to the blood supply of the paracaval portion and Spiegel lobe originating from left hepatic artery or middle left hepatic artery, while the other one contributes to the blood supply of the caudate process originating from right hepatic artery. Other studies have shown that there is a confluence between the arteries of the CL and the arteries around the bile duct, which indicated that hepatic portal occlusion should be selected for the caudate lobectomy. In this study, a selfdesigned tube was used for the hepatic portal occlusion via the first porta hepatis, in order to block the blood supply in the porta hepatis in an intermittent manner. Such method induced less blood loss and prevented liver ischemiareperfusion injury.

The venous vein of the CL is usually conformed into the IVC in the form of the SHV, which is featured by thin vascular wall, short trunk, and a deep location [34]. There are usually two to four SHV injected into the left and right side of the IVC. The thick SHV is usually localized at the middle and lower parts of the CL; however, no SHV is noticed in the upper part. Therefore, a safe passage can be established between the bilateral SHV and the superior right hepatic artery $[10,12]$.

The argon knife can be used for the hemostasis at the liver surface. Compared with the previous techniques, the argon knife contributes to quick hemostasis and less tissue injury, which then reduces the surgical duration and possibility of postoperative hemorrhage [35]. Meanwhile, argon knife showed satisfactory killing effects on the resident cancer cells. For those received laparoscopic caudate lobectomy, the procedures promoted the successful rate in the presence of a limited surgical field. In cases of poor hemostasis using argon knife, some options should be selected such as vascular clamp and suturing.

Liver is an important source for the synthesis of coagulation factors. When liver function was impaired, the coagulation factor synthesis was downregulated, which then resulted in decreased scavenging of the tissue thromboplastin and the activated fibrinolytic factors, as well as prothrombin time 
(PT) and INR. Some patients showed higher PT and INR after surgery compared with the baseline level, indicating that the operation had some damage to liver function. Meanwhile, the operation showed less damage to coagulation function. In some patients, bilirubin showed an upward trend on days 1 and 3 compared with the baseline levels, which may be related to the partial liver tissue injury. Fortunately, the bilirubin level decreased on day 5. Most of the postoperative patients showed a decrease in albumin on days 1 and 3 , which may be related to the surgical trauma and the nutritional status of postoperative patients. However, the degree of reduction is not significant, indicating that the operation had less damage to albumin synthesis.

In summary, laparoscopic caudate lobectomy contributed to the attenuation of wound and decrease in hospitalized duration. Based on our experiences, laparoscopic caudate lobectomy is safe in clinical practice after understanding its indications and presence of complete presurgical preparation.

\section{Conflicts of Interest}

The authors declare that they have no conflicts of interest.

\section{Acknowledgments}

This study was supported by the National Natural Science Foundation of China (Grant no. 81571367), the research project of Qilu Hospital (Grant no. 2014qlky18), and the Shandong scientific and technological research program (Grant no. 2016GSF201082).

\section{References}

[1] H. Reich, F. McGlynn, J. DeCaprio, and R. Budin, "Laparoscopic excision of benign liver lesions," Obstetrics \& Gynecology, vol. 78, no. 5, pp. 956-958, 1991.

[2] W. Wayand and R. Woisetschlager, "Laparoscopic resection of liver metastasis," Chirurg, vol. 64, no. 3, pp. 195-197, 1993.

[3] M. Casaccia, F. Famiglietti, E. Andorno, S. Di Domenico, C. Ferrari, and U. Valente, "Simultaneous laparoscopic anterior resection and left hepatic lobectomy for stage IV rectal cancer," Journal of the Society of Laparoendoscopic Surgeons, vol. 14, no. 3, pp. 414-417, 2010.

[4] T. Yamamoto, S. Kubo, T. Shuto et al., "Surgical strategy for hepatocellular carcinoma originating in the caudate lobe," Surgery, vol. 135, no. 6, pp. 595-603, 2004.

[5] E. Chaib, M. A. F. Ribeiro Jr., F. D. S. C. Silva, W. A. Saad, and I. Cecconello, "Caudate lobectomy: tumor location, topographic classification, and technique using right- and left-sided approaches to the liver," The American Journal of Surgery, vol. 196, no. 2, pp. 245-251, 2008.

[6] W. Zheng, D. Zi-Hai, Z. Jie, Z. Shi-Zhen, L. Jian-Hua, and L. Yi-Xiong, "Anatomy of the retrohepatic tunnel in a Chinese population and its clinical application in liver surgery," Scientific Reports, vol. 7, Article ID 44977, 2017.

[7] K. Kogure, H. Kuwano, H. Yorifuji, H. Ishikawa, K. Takata, and M. Makuuchi, "The caudate processus hepatic vein: A boundary hepatic vein between the caudate lobe and the right liver," Annals of Surgery, vol. 247, no. 2, pp. 288-293, 2008.
[8] K. Araki, D. Fuks, T. Nomi et al., "Feasibility of laparoscopic liver resection for caudate lobe: technical strategy and comparative analysis with anteroinferior and posterosuperior segments," Surgical Endoscopy, vol. 30, no. 10, pp. 4300-4306, 2016.

[9] T. T. Cheung, "Technical notes on pure laparoscopic isolated caudate lobectomy for patient with liver cancer," Translational Gastroenterology and Hepatology, vol. 2016, no. JULY, 2016.

[10] H. Inamori, K. Ido, N. Isoda et al., "Laparoscopic radiofrequency ablation of hepatocellular carcinoma in the caudate lobe by using a new laparoscopic US probe with a forward-viewing convex-array transducer," Gastrointestinal Endoscopy, vol. 60, no. 4, pp. 628-631, 2004.

[11] E. C. H. Lai and C.-N. Tang, "Robot-assisted laparoscopic partial caudate lobe resection for hepatocellular carcinoma in cirrhotic liver," Surgical Laparoscopy Endoscopy \& Percutaneous Techniques, vol. 24, no. 3, pp. e88-e91, 2014.

[12] C. Kyriakides, N. Panagiotopoulos, and L. R. Jiao, "Isolated laparoscopic caudate lobe resection," Surgical Laparoscopy Endoscopy \& Percutaneous Techniques, vol. 22, no. 4, p. e209, 2012.

[13] B. Jin, D. U. Gang, and B. H. Zhou, "Clinical application of laparoscopic resection in hepatic caudate lobe tumor:with a report of 5 cases," Journal of Laparoscopic Surgery, 2017.

[14] X. Cai, J. Zhao, Y. Wang et al., "A left-sided, purely laparoscopic approach for anatomic caudate hepatectomy: a single-center experience," Journal of Laparoendoscopic \& Advanced Surgical Techniques, vol. 26, no. 2, pp. 103-108, 2016.

[15] E. Gringeri, R. Boetto, D. Bassi et al., "Totally laparoscopic caudate lobe resection: Technical aspects and literature review," Surgical Laparoscopy Endoscopy \& Percutaneous Techniques, vol. 24, no. 6, pp. e233-e236, 2014.

[16] A. Zarzavadjian Le Bian and F. Borie, "Caudate lobe resection: The laparoscopic approach (with video)," Journal of Visceral Surgery, vol. 152, no. 2, pp. 135-136, 2015.

[17] C. Salloum, E. Lahat, C. Lim et al., "Laparoscopic Isolated Resection of Caudate Lobe (Segment 1): A Safe and Versatile Technique," Journal of the American College of Surgeons, vol. 222, no. 5, pp. e61-e66, 2016.

[18] U. Kokkalera, A. Ghellai, and T. J. Vandermeer, "Laparoscopic hepatic caudate lobectomy," Journal of Laparoendoscopic \& Advanced Surgical Techniques, vol. 17, no. 1, pp. 36-38, 2007.

[19] K. M. Ho, H. S. Han, Y. S. Yoon et al., "Laparoscopic total caudate lobectomy for hepatocellular carcinoma," Journal of Laparoendoscopic Advanced Surgical Techniques Part A, 2016.

[20] D. Oh, C. H. Kwon, B. G. Na et al., "Surgical techniques for totally laparoscopic caudate lobectomy," Journal of Laparoendoscopic Advanced Surgical Techniques Part A, vol. 26, no. 9, p. 689, 2016.

[21] Y. S. Yoon, H. S. Han, S. H. Shin et al., Total Laparoscopic Liver Resection for a Metastatic Lesion Located in the Caudate Lobe, 2007.

[22] C. Jiang, G. Y. Wang, and M. Wang, "One case report of laparoscopic resection of caudate lobe hepatocellular adenoma," Journal of Clinical Hepatology, 2012.

[23] K.-H. Chen, K.-S. Jeng, S.-H. Huang, and S.-H. Chu, "Laparoscopic Caudate Hepatectomy for Cancer-An Innovative Approach to the No-Man's Land," Journal of Gastrointestinal Surgery, vol. 17, no. 3, pp. 522-526, 2013.

[24] T. Asahara, K. Dohi, H. Hino et al., "Isolated caudate lobectomy by anterior approach for hepatocellular carcinoma originating in the paracaval portion of the caudate lobe," Journal of HepatoBiliary-Pancreatic Sciences, vol. 5, no. 4, pp. 416-421, 1998. 
[25] T. Ishizawa, A. A. Gumbs, N. Kokudo, and B. Gayet, "Laparoscopic segmentectomy of the liver: From segment i to VIII," Annals of Surgery, vol. 256, no. 6, pp. 959-964, 2012.

[26] A. J. Koffron, G. Auffenberg, R. Kung, and M. Abecassis, "Evaluation of 300 minimally invasive liver resections at a single institution: Less is more," Annals of Surgery, vol. 246, no. 3, pp. 385-392, 2007.

[27] M. Kumon, "Anatomy of the caudate lobe with special reference to portal vein and bile duct," Acta Haematologica Japonica, vol. 26, no. 9, pp. 1193-1199, 1985.

[28] F. F. Coelho, J. A. P. Kruger, G. M. Fonseca et al., "Laparoscopic liver resection: Experience based guidelines," World Journal of Gastrointestinal Surgery, vol. 8, no. 1, p. 26, 2016.

[29] P. Arumugam, V. Balarajah, J. Watt, A. T. Abraham, S. Bhattacharya, and H. M. Kocher, "Role of laparoscopy in hepatobiliary malignancies," Indian Journal of Medical Research, vol. 143, no. April, pp. 414-419, 2016.

[30] G. C. Sotiropoulos, N. Machairas, P. Stamopoulos et al., "Laparoscopic versus open liver resection for hepatocellular carcinoma: Initial experience in Greece," Annals of Gastroenterology, vol. 29, no. 4, pp. 521-529, 2016.

[31] E. Alkhalili and E. Berber, "Laparoscopic liver resection for malignancy: A review of the literature," World Journal of Gastroenterology, vol. 20, no. 37, pp. 13599-13606, 2014.

[32] J.-L. Dulucq, P. Wintringer, C. Stabilini, and A. Mahajna, "Isolated laparoscopic resection of the hepatic caudate lobe: surgical technique and a report of 2 cases," Surgical Laparoscopy Endoscopy \& Percutaneous Techniques, vol. 16, no. 1, pp. 32-35, 2006.

[33] S.-Y. Peng, J.-T. Li, Y.-P. Mou et al., "Different approaches to caudate lobectomy with "curettage and aspiration" technique using a special instrument PMOD: A report of 76 cases," World Journal of Gastroenterology, vol. 9, no. 10, pp. 2169-2173, 2003.

[34] C. Afaneh and M. D. Kluger, "Laparoscopic liver resection: Lessons at the end of the second decade," Seminars in Liver Disease, vol. 33, no. 3, pp. 226-235, 2013.

[35] J. Sperling, C. Ziemann, J. Schuld et al., "A comparative evaluation of ablations produced by high-frequency coagulation-, argon plasma coagulation-, and cryotherapy devices in porcine liver," International Journal of Colorectal Disease, vol. 27, no. 9, pp. 1229-1235, 2012. 


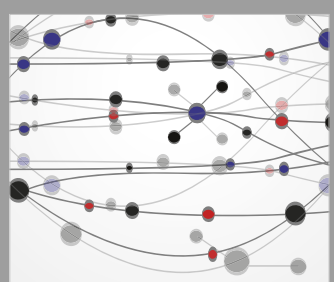

The Scientific World Journal
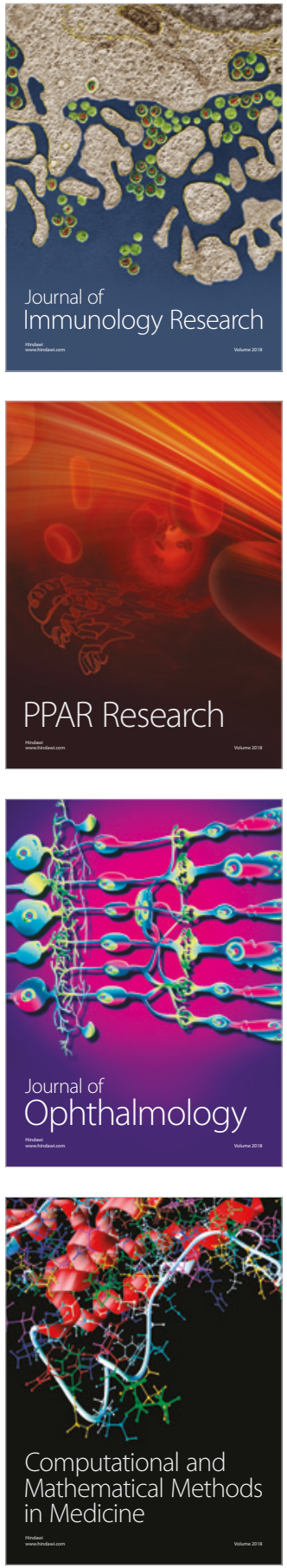

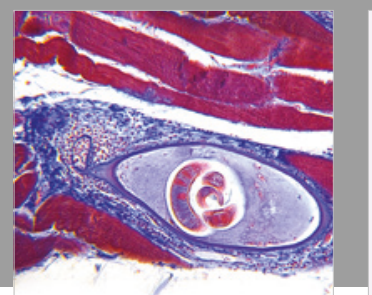

Gastroenterology Research and Practice

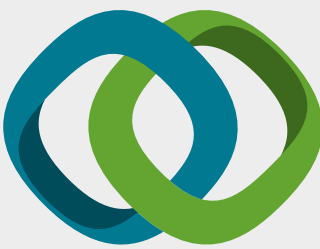

\section{Hindawi}

Submit your manuscripts at

www.hindawi.com
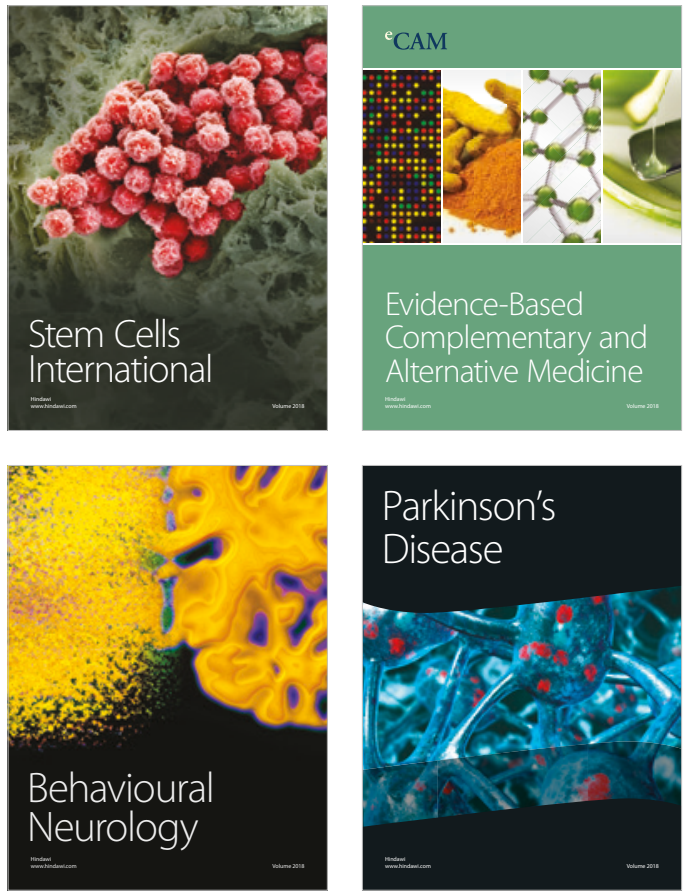

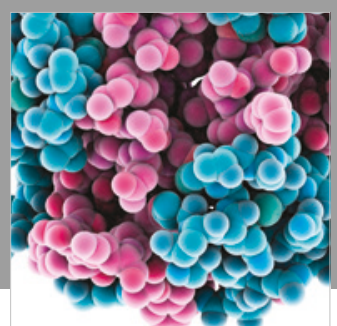

ournal of

Diabetes Research

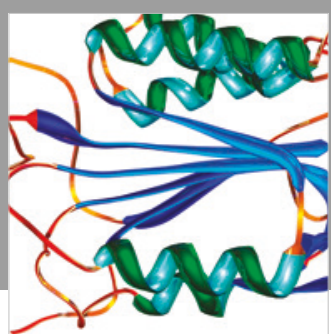

Disease Markers
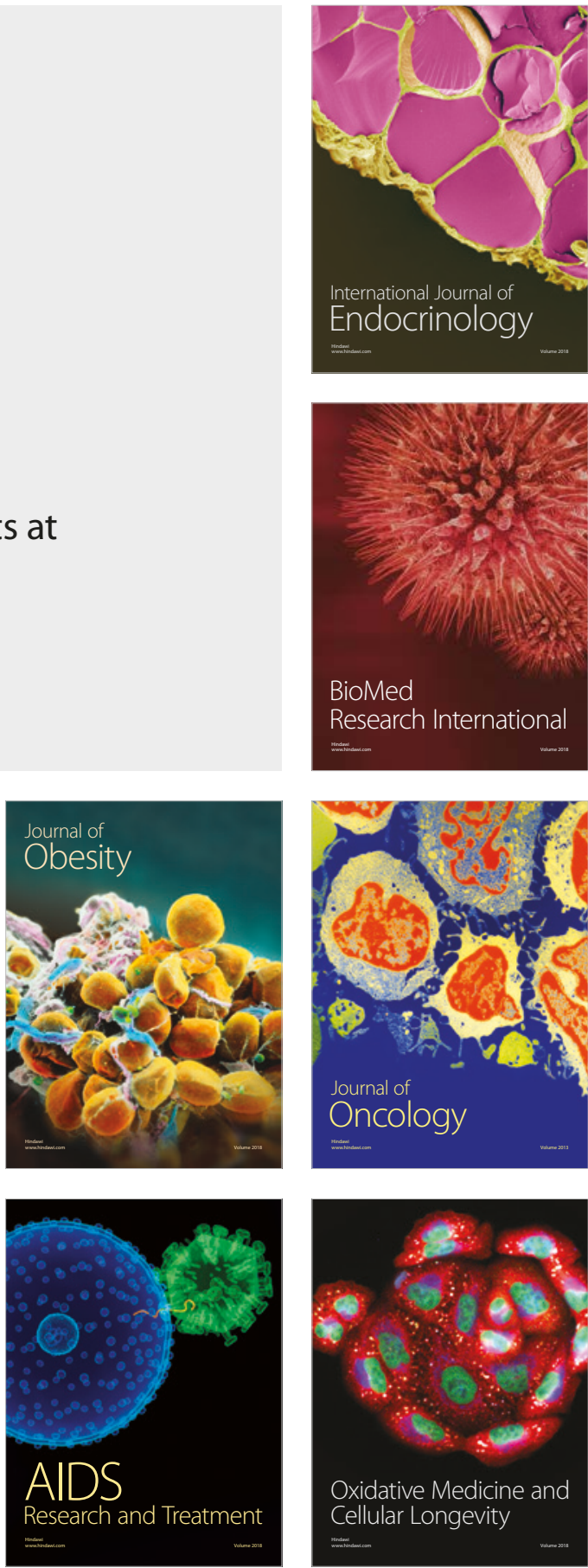